\title{
ALTERNATIVE CONCEPTIONS OF POVERTY AND THEIR IMPLICATIONS FOR INCOME MAINTENANCE*
}

\author{
SEYMOUR SPILERMAN and DAVID ELESH \\ University of Wisconsin
}

\begin{abstract}
This paper speaks to the problem of designing income maintenance programs from the perspective of sociological theory. First, the underlying logic of situational and cultural theories of poverty is delineated, and some of their general implications are explored. Afterwards, the predictions of these theories with respect to the response by poor persons to an income maintenance program are examined. It is argued that, in place of seeking whether one or the other type of explanation is valid in general, we ascertain for which groups in poverty and for what types of response a particular theory is likely to be more useful. The discussion is illustrated by a consideration of how an individual's response to income maintenance is likely to vary with ethnicity and neighborhood organization.
\end{abstract}

\section{INTRODUCTION}

In the narrowest use of the term, living in poverty means having low income. As a concern of social agencies and social scientists, however, poverty is associated with a range of disabilities, some spawned by low income, others producing this condition. Psychologically, poor persons are likely to feel powerless, have low self-esteem, have short temporal horizons, and be weakly motivated in their occupational roles. At the level of individual behavior, low income is associated with inadequate nutrition, poor health care, living in dilapidated housing, unemployment, economic dependency, illegitimacy and crime-to cite but a few concomitants. Poverty-ridden communities have some characteristics which are aggregates of these individual level disabilities-high rates of unemployment, crime, economic dependencybut also others which emerge only in a context of dense concentrations of poor persons, such as gang delinquency

* The research reported here was supported by funds granted to the Institute for Research on Poverty at the University of $W$ isconsin by the Department of Health, Education, and Welfare, contract number SRS-69-36. We wish to thank Harold Watts and Jerald Hage for their criticisms of an earlier draft of this paper. The conclusions are the sole responsibility of the authors. and a paucity of formal organizations to advocate interests which are shared by residents of a neighborhood.

Income definitions of poverty are attractive for a number of purposes. They provide explicit criteria for measuring the prevalence of poverty, for charting over-time changes in the size of the poverty population, and for estimating the financial cost of eliminating this condition, at least in the sense of raising low income families to the subsistence level. Income definitions are also useful to researchers who are principally concerned with the social disabilities which often accompany low income since they provide a convenient summary indicator of the magnitude of these problems.

At least in part, the motivation behind eliminating poverty stems from a concern with alleviating some of the correlative disabilities of low income. The presence of poor persons in a society creates substantial costs for the more affluent who not only must sustain the impoverished but suffer their asocial behavior as well. Many programs in the panoply of social welfare have, therefore, been designed to combat disvalued behavior of one sort or another which accompanies low income (delinquency, illegitimacy) rather than alter the income level itself. 
However, the fact that a syndrome of conditions carries a name which designates an income state-povertysignifies the prevailing assumption as to the interrelations among the specific variables, namely that low income somehow plays a central role in the perpetuation of these conditions. Consistent with this perspective, a range of social welfare programs have been directed at altering factors which impinge upon income-job training, antidiscrimination laws in hiring, and job creation. (For a review of these programs see Elesh, Ladinsky, Lefcowitz, and Spilerman, 1970.) In recent years, however, attention has focused more upon the advisability of manipulating the income variable directly, rather than factors related to it, however closely. Reflecting this interest, income maintenance programs are currently undergoing field experimentation in New Jersey, Pennsylvania, Washington, Iowa, and North Carolina.

Income maintenance programs, indeed all plans which propose to eliminate a syndrome of conditions by manipulating one or a few variables, embody specific assumptions about the interrelations among the variables. Implicit in an income maintenance policy is the belief that many correlative characteristics of low income can be altered by an exogenous intervention which raises family income; in short, that income level is an antecedent variable in a causal relationship between low income and other poverty characteristics. If this assumption is correct, income maintenance could provide an efficient strategy for treating a range of social problems since only a single variable would need to be manipulated. On the other hand, if this assumption as to the variable linkages is wrong and the correlative characteristics of low income prove intractable to income adjustments, we will find ourselves contending with these same problems under a new label such as "disabilities of the near-poor."

Unfortunately, we have only limited experience with income support programs that are not restricted to narrow categories of the destitute who are incapable of significantly altering their work behavior (e.g., the incapacitated, the aged, and female heads of families). When applied more broadly, it is likely that some correlates of povexty-hunger, insufficient clothing, poor health care-could be quickly eliminated, but what about factors which are only indirectly related to family income such as educational aspirations of the young, sense of personal efficacy, family stability, and delinquency? Can we expect fewer family breakups or a decrease in illegitimacy under income maintenance? Also, how long will it take for these responses to develop if, indeed, it is reasonable to expect such changes?

Analogous questions can be raised concerning the variation across individuals in response to an income maintenance program. Economists have been primarily interested in the average individual adjustment. However, it is conceivable that different persons in the poverty population will adapt to income support in very different ways. If the variation is indeed large then the simplification of the welfare structure which would be achieved by adopting a uniform national program of income maintenance would be attained at the cost of not meeting the needs of a great many poor persons.

The intent of this paper is to discuss some of the dimensions along which individual variation in response to an income maintenance program is likely 
to occur, and to indicate the relevance of different explanations of poverty to experimentation in income maintenance. Our perspective here is that (a) the different poverty theories predict divergent adaptations by recipients of income maintenance, (b) a given explanation of poverty is likely to be valid for some individuals but not for others, and only for particular correlates of low income, and (c) much of the inter-individual variation can be attributed to differences in response among social groups. Consequently, we propose that future research should be directed at identifying the characteristic types of adaptations which are likely to occur, and associating particular groups in poverty with each adaptation.

\section{Alternative Theories OF POVERTY}

Theories of poverty are broadly of two types, situational (commonly characterized by simple causality) and cultural (functional). Situational explanations view the behavioral characteristics of low income individuals as an adaptation to environment and circumstance. If a poor person tends not to defer gratification and invest in the future, it is because the future is precarious for him, too unstable for a long range perspective to be rational. If he mugs for a living, it is because the socially acceptable occupations which show similar financial returns are outside the pale of vocations available to him. Thus, the view that the destitute share a deviant culture, with values which are in opposition to those of the dominant society, is not invoked. The fact that in seemingly diverse settings poor persons exhibit similar behavioral characteristics is taken as evidence for their having to contend with analogous problems which permit few alternative adaptations, rather than their holding like deviant values.

By comparison, cultural explanations of poverty argue that the behavior and attitudes of poor persons are components of a coherent life style. These factors are seen as an expression of established rules or norms which prescribe what is desirable or important, rather than as an application of general societal values to the circumstance of the poor. Since cultural theories explain behavior and attitudes in terms of concepts like values, expectations and social pressure, cultural theories of poverty take the guise of "functional explanations." 1 From this perspective, then, the poor in different settings behave in a similar fashion because they share common values.

These two types of explanations have very different underlying logical structures and often imply contradictory adaptations by recipients of income maintenance. Since our interest here is with developing the implications of the different theories by examining their logical structures, the substantive examples that are considered in the following sections will necessarily be elementary and are intended for illustrative purposes.

Situational explanations-In their most elementary form, situational explanations which relate low income to correlative behavioral characteristics may be paradigmed as causal sequences. For example, low and variable income leads to insufficient nutrition and inadequate housing, which result in poor health, impairing, in turn, the individ-

1 Following Stinchcombe (1968:80-85), we identify a functional explanation with a self-adjusting system which involves negative feedback. This point is elaborated in the following section. 
ual's ability to work. Or, low income implies inadequate home study conditions for children, poor nourishment, and a continual state of financial need by the family, which combine to reduce a child's ability to concentrate on school affairs. In each of these chains, as in causal theory generally, there is an implication that by manipulating a prior factor, the variable of primary interest can be altered; that an increase in family income would be translated into an improvement in work performance in the first illustration, and into an increase in scholastic attainment in the second example.

In order to obtain the most return from an intervention, it is vital that the variable chosen for manipulation be prior to most of the conditions which one is interested in altering. Thus, in the first example, if one improves the state of health of an individual by bringing exogenous factors to bear which impinge directly on health-providing vitamin pills rather than raising income--only the variables subsequent to state of health (the individual's work performance) will be improved by the manipulation. By intervening earlier in the causal sequence, however, (in this illustration by raising family income) a large number of factors can be altered with. out particular attention having to be given to these disabilities. From the perspective of altering the behavioral concomitants of poverty, then, an income maintenance program represents an assumption as to the causal ordering, namely that family income is causally prior to many of the other elements in the constellation of poverty characteristics. ${ }^{2}$

2 Likewise, alternative proposals for combating poverty-job training, more effective schooling, maintaining a tight labor mar-
There is another form of causal explanation, often employed in studies of the intergenerational transmission of poverty, in which it is less apparent that the link at which the intervention should occur is material. I refer to the "cycle of poverty" explanations (U.S. Department of Labor, 1965: 47; House Committee on Education and Labor, 1964: 49). If a causal sequence can be closed by adding links to connect the final and initial variables (in the first illustration, low capacity to work can be linked to inadequate income in the succeeding time period; in the second, low academic attainment implies poor labor market sitution which results in inadequate income), then, theoretically, intervention can be made at any link with a consequent improvement in the levels of all factors. In practice, however, even where a cycle provides a valid representation of reality, ${ }^{3}$ the selection of a variable for manipulation remains an important decision because the cost of intervention can differ considerably by link, and because societal values are more permissive of some manipulations (e.g., raising educational attainment, income maintenance) than of others (e.g., limiting family size).

More complex situational explanations can be represented as path models. Recent empirical work on the intertions can be represented as path models. relations among poverty associated characteristics have used this methodology

ket-represent different assumptions as to the causal ordering.

3 It should be noted that where a cycle of poverty explanation is appropriate, the relationships must necessarily be nonlinear. For example, in the first illustration, after a certain period of time a unit increase in an individual's level of health must have a negligible impact on his work performance. Otherwise, the system of relationships would "explode," resulting in infinite health and commensurate income. 
(Duncan, 1969; Duncan, Featherman, and Duncan, 1968). It must be recognized that the use of a causal methodology such as a recursive system of equations represents an assumption regarding the validity of a situational explanation. A path model enables the variation in the dependent variable to be partitioned among the several paths (causal sequences). Only rarely, however, can the suitability of the underlying causal framework be tested. ${ }^{4}$

There is a considerable literature, both theorizing and research, in support of a situational explanation for the behavioral and attitudinal correlates of poverty. In a now classic essay, Merton (1957) introduced a five-fold typology relating the goals which are pursued by individuals to the means employed. Merton contends that where the societal goals are accepted but the sanctioned means are unavailable, an innovative response-the use of illicit means-is likely to ensue. Applying this perspective to the poor, it would appear that precisely the individuals who subscribe to the middle-class conception of success-wealth and its appurtenances, to put matters crudelywould be most likely to resort to illegitimate means. Conversely, if well paid and steady work were available in the "respectable labor market," the muggers and pimps could presumably

4 Sewell Wright's (1960a) comment on the interpretation of a path coefficient which is greater than one is suggestive of the operation of negative feedback and may provide a test for this condition. Wright (1960a:194-5) writes, "Such a value shows at a glance that direct action of the factor in question is tending to bring about greater variability than is actually observed. The direct effect must be offset by opposing correlated effects of other factors." Compare this statement with the discussion pertaining to Figure 1 in this paper. be enticed away from their current vocations.

Support for a situational perspective is also provided by Miller, Riessman, and Seagull (1968). They argue that while impulse following and a preference for immediate gratification are characteristics of lower-class life styles, this behavior derives from the opportunity structure facing the poor, rather than from distinctive cultural values on their part. For a middle-class person the world is orderly and stable, making an investment in the future relatively secure and economically ra. tional. By comparison, the present-time orientation of poor persons is a calculated response to an unstable reward structure, a world characterized by garnishment and unemployment. In this circumstance, one might well choose to get his kicks while he could rather than plan for extensive gratifcation in the future. Thus, in this view, it is not so much different orientations to time which account for the differential class tendency to invest in the future as it is the different futures of the poor and the affluent.

Liebow (1967:58), in a study of Negro men who hang out at a particular streetcorner, provides compelling descriptive evidence for the impact of the opportunity structure on their behavior, although in values and attitudes toward work the men are essentially middle class. Liebow argues that the lethargy and disinterest which these individuals bring to the job is due to their acceptance of the dominant societal values toward work. The jobs to which they have access are, typically, "hard, dirty, uninteresting and underpaid." More importantly, they are dead-end jobs, not stepping stones to better positions even for those who are willing to do them faithfully. "The 
busboy or dishwasher in a restaurant is not on a job track which, if negotiated skillfully, leads to chef or manager of the restaurant. The busboy or dishwasher who works hard becomes, simply, a hard working busboy or dishwasher" (1967:63). The disdain which these men have toward their work, then, is no different from the view which middle-class individuals accord to these same positions; they are accurately reflecting the values of the society.

These works are illustrative of research supporting a view of poverty which attributes the behavioral characteristics of poor persons to their material situation. The poor are not seen as carriers of an independent culture with values and aspirations that are at variance with those of middle-class society. Rather, their behavior deviates from established norms because the application of the societal values to their circumstance leads to different results. One immediate implication of situational theory for income maintenance is that the characteristics of low income individuals which are causally subsequent to income level will respond to a change in this variable. Indeed, it is expected that the resulting adaptation would approximate middleclass mores since, by assumption in this explanation, the values of the poor are not different from those of more affluent persons.

However, situational theory does not suggest what the waiting time would be for a particular response to income maintenance to develop. It is basically a theory of static relationships and rarely directs attention to the dynamic behavior of the adjustment process. Assuming the appropriateness of the situational assumption, other questions which must be addressed, in order to construct a particular situational ex- planation, concern the location of the income variable in the causal sequence, and the manner in which the linkage among variables differs by individual. These and related matters which impinge upon income maintenance are discussed after the logic of the cultural explanations has been outlined.

Cultural explanations-The main contrary thesis to situational explanations is represented by the cultural theories. In this perspective, individuals living in poverty share distinctive values and aspirations which set them apart from the dominant culture. Some of the values which are characteristic of this subculture are action seeking, impulse following, a strong present-time orientation, belief in luck or fate, and a predisposition toward authoritarianism (Lewis, 1966:xlviii). As derivative attributes, individuals subscribing to these values are generally hostile toward education (which is incompatible with action seeking and an orientation toward present-time gratification) and unable to identify with a job as a career.

Culture of poverty explanations, like much of functional theory, are weak in their ability to account for the emergence of the culture. The commonly presented view is that a poverty culture originates when a population has been economically depressed for a very long period of time (Lewis, 1966:xliv). In this situation, values and aspirations develop which allow the population to achieve some modicum of success or status even in their deprived state. Individuals decide that the really important goals are ones which they can attain, that the standards according to which they should measure themselves are ones which they can reasonably compete for. Albert Cohen (1955: 121) describes the adolescent gang 
culture in this vein: "Certain children are denied status in the respectable society because they cannot meet the criteria of the respectable status system. The delinquent subculture deals with these problems by providing criteria of status which these children can meet."

One assumption common to cultural explanations is that the values originating in this manner attain an existence which is relatively independent of the situational considerations which gave them birth. Moynihan (1966: 155) suggests such a development in his controversial work on the Negro family. He is concerned with "whether the impact of economic disadvantage on the Negro community has gone on for so long that genuine structural change has occurred, so that a reversal in the course of economic events will no longer produce the expected response in social areas." $\mathrm{He}$ suggests that "three centuries of injustice have brought about deep-seated structural distortions in the life of the Negro American. At this point, the present tangle of pathology is capable of perpetuating itself without assistance from the white world" (U.S. Dept. of Labor, $1965: 47)$. It is not our intention here to enter into a discussion concerning the substantive merit of his argument, ${ }^{5}$ only to illustrate a typical presentation of the origin of a culture of poverty. ${ }^{\circ}$

b For extensive commentaries on Moynihan's analysis, see Rainwater and Yancey, (1967) or Valentine, (1968).

6 To our knowledge, Moynihan never explicitly claims that a coherent culture with institutionalized values has come into existence as a result of the many years of deprivation and neglect. He speaks of structural changes which are capable of perpetuating themselves, terms which are suggestive of a cultural explanation. They are also consistent, however, with a "psychological maiming" argument (see following section) which does not assume the presence of autonomous cultural standards.
The essential feature of a culture of poverty argument is that the value structure forms a self-maintaining system which perpetuates itself from generation to generation. By a self-maintaining value system we mean one in which the dominant norms and aspirations are accepted by members of the group, are interrelated in such a way as to sustain one another in an individual's internal organization of values, and are reinforced through social pressure upon deviants in the value setting institutions of the group (e.g., family, streetcorner gang). The most explicit formal representation of a self-maintaining system, or functional relationship, is given by Stinchcombe (1968). (Also see Coleman (1968:439) on a methodology for analyzing functional relationships.) In this conceptualization, a particular variable (the homeostatic variable) is maintained at a constant level due to the activity of a negative feedback structure despite the action of forces attempting to alter it (exogenously induced change).

We can illustrate this arrangement by considering how an income support program might fail to produce a particular consequence such as raising the scholastic performance of children. Normally, an increase in disposable income would be expected to promote higher academic attainment by children in the household (presumably through the intervening variables discussed earlier in the illustrative causal chain). However, if an adolescent belongs to a peer group which rewards manliness, emphasizes immediate gratification, and scorns scholastic interests, then we might expect the exertion of peer group pressure to offset the increased opportunity to concentrate on academic concerns. Figure 1 illustrates this situation. The improvement in scholastic performance which is expected from 
income maintenance (positive effect) induces peer group pressure in opposition to this activity (positive effect) which, in turn, compels the child to reduce his involvement with education (negative effect), maintaining scholastic performance at near its original level. Assuming magnitudes of the individual effects equalling $A, B$, and $C$ as indicated in Figure 1, it can be shown (Stinchcombe, 1968:136-38) that the net contribution from an income change of magnitude $A$ upon scholastic performance will equal A $1-B C$

denominator of the fraction is greater than one and $\frac{A}{1-B C}<A$, the effect which is expected from income maintenance in a simple causal relation.?

In this manner, the interrelations within the value system and the presence of cultural institutions which support the traditional values can offset

7 As Figure 1 suggests, non-recursive path models would probably provide an appropriate methodology for studying the effects of cultural factors on the perpetuation of poverty. No empirical work of this nature is known to the authors. For a discussion of the relevant methods consult Wright (1960b).

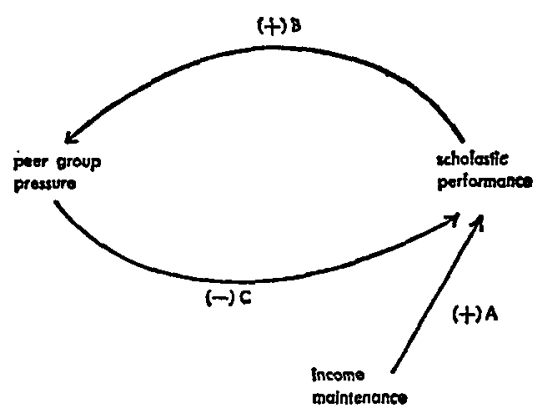

FIGURE I: Illustration of a functional explanation exogenously induced change and inhibit the effect one would expect from a causal relationship. This is one essential notion of the culture of poverty concept. A second relates to the process by which poverty is perpetuated. The preceding discussion of situational explanations suggested that the intergenerational inheritance of poverty could result from children having to adapt to the same environment as their parents before them, and making similar adjustments. In a culture of poverty explanation, by comparison, the transmission is through socialization of the young into the value system of their parents. Oscar Lewis (1966:xiv) writes, "By the time slum children are age six or seven, they have usually absorbed the basic values and attitudes of their subculture and are not psychologically geared to take full advantage of changing conditions or increased opportunities which may occur in their lifetime."

According to a culture of poverty argument, then, a set of values has come into existence (perhaps as an adaptation to having lived in poverty for a long period) which discourages certain behavior such as investing time in education or developing a career orientation toward work. Were social agencies to intervene and increase the payoff or the probability of a return from these actions (by providing income maintenance to make the future more determinate and deferral of gratification more rational) the cultural values which support the status quo would be stressed by the traditional institutions of the group. Supplementing the effects from socialization to these values, individuals would be reminded of their obligations to kin, friends, and tradition, and thereby socially pressured to refrain from adopting life styles which are disvalued in 
the culture. ${ }^{8}$ As a consequence, one implication of a cultural explanation of poverty for income maintenance programs is that the behavioral correlates of low income may prove intractable to these manipulations and have to be treated directly. This, incidentally, is the type of policy recommendation which Moynihan makes in his assessment of the Negro family structure (U.S. Dept. of Labor, 1965); and, in the context of a cultural explanation, it is an appropriate conclusion.

Conceptual distinctions between these explanations-In practice, circumstances in which a situational explanation provides an appropriate assessment for why individuals remain in poverty can be difficult to distinguish from ones in which a cultural explanation is valid. One reason is that "psychological maiming" may have occurred, and this would prevent individuals from responding to a change in conditions (such as might be provided by income maintenance), although one would predict such response from the values which they hold.

Psychological maiming refers to the complete demoralization of an individual as a result of repeated failure in the main institutions of society. For example, Liebow (1967:54) reports that the experience of being a dropout from school, continually having difficulty to find satisfying work, and failing to support adequately one's family, often generates low self-esteem and a fear of being tested. "Convinced of

8 These mechanisms of social control are common to religious sects which try to maintain unambiguous boundaries between themselves and the secular society. Neither the Amish nor many Hasidic groups (Poll, 1962:147) would be likely to encourage university education for their youth even if it were offered free. their own inadequacies, not only do they not seek out those few better pay. ing jobs which test their resources, but they actively avoid them, gravitating in a mass to the menial, routine jobs which offer no challenge-and, therefore, pose no threat-to the already diminished images they have of themselves."

In this circumstance, the values to which the individual is socialized are those of the dominant culture, yet his ability to respond to an altered situation is drastically impaired. In Merton's (1957:153) paradigm, the condition is one of withdrawal or retreatism, and is exemplified by the "disreputable poor," the dregs, drifters, and hoboes. According to Gans (1969: 224-34), persons in this circumstance must be aided in reestablishing a link between values and behavior. "How much security, economic and other, must be provided for how long before people can take the risk of grasping at new opportunities and be able to give up present behavioral norms and associations?" Thus, the failure of an expected response to eventuate from a change in environment can result either when a causal explanation is correct but the linkage between the variables has been attenuated (psychological maiming), or when a functional (cultural) explanation is appropriate and the variable of interest is maintained at an approximately constant level through negative feed. back.

Second, in circumstances for which a situational explanation is appropriate, the time to adjustment following the introduction of income maintenance may be considerable, incorrectly suggesting the operation of cultural values and aspirations which counter the requisite behavior for exploiting new 
conditions. However, the essence of a situational explanation is not that adjustments to an exogenous change are immediate; rather it is an absence of negative feedback structures which impede the adjustment. Thus, some behavioral correlates of low income, such as an inability to defer gratification, may be slow to disappear because poor persons may require several years of evidence that the income support payments are not a transitory phenomenon. Other possible adjustments, such as an increase in educational attainment by the family head, are unlikely ever to develop, even in the absence of cultural interference. The location of these individuals in the life cycle no longer permits a major response on this dimension. Unfortunately, existing analyses of adjustments to exogenously induced change rarely consider the dynamic aspects of the response (see Lieberson and Fuguitt (1967) for a contrary instance). These studies are largely cross-sectional and focus on changes in the equilibrium relationships.

Third, even where a cultural explanation is appropriate, by drastically altering the environment, a causal response to the manipulated variable can often be effected. A self-regulating system such as a culture can maintain behavioral patterns homeostatically only for limited ranges of exogenously induced change. Therefore, concerning culturally supported behavior, the appropriate question is not whether it can be altered by exogenous manipulations but how extensive an input would be necessary. What is required is either a disintegration of the cultural values which normally prevent the response, which will occur if the traditional patterns are no longer viable in the altered context, or a readjustment of the cul- ture to a new equilibrium in which the intended behavior is sanctioned (redefinition of the values). If alternative adaptations to a new situation are few, it is likely that the equilibrium would be in the direction of the dominant societal values, since these represent one adaptation with which all individuals have some familiarity. To illustrate, it may not be necessary to treat the instability of the Negro fam. ily directly, as Moynihan (1966) contends. Even accepting his evidence concerning the lack of responsiveness of the Negro family's stability to economic conditions, an extensive alteration of employment opportunities and the welfare structure may accomplish this purpose if it makes the matrifocal family less viable.

\section{ELABORATIONS AND IMPLICATIONS FOR RESEARCH ON INCOME MaINTENANCE}

In the preceding sections we have reviewed the logic of the main types of poverty theories and have indicated some immediate inferences to be drawn for an income maintenance program. However, the discussion has been superficial in two ways. First, we have not differentiated among the various groups of persons in poverty to allow for the possibility that while a situational explanation may be appropriate to the circumstance of some, a cultural explanation may provide more accurate predictions of the response by others. Second, explanations should probably be behavior specific as well as population specific. As Gans (1969: 209) has pointed out it is a mistake to view culture as a holistic system. In any culture some areas of behavior will tap few values or mores and, therefore, will respond situationally to ex. ogenous interventions, while in other 
areas the culture will rigidly prescribe what is appropriate behavior.

Some early researchers into the relation between culture and poverty conceived of a universal poverty culture. Oscar Lewis (1966:xlviii), who has presented the most elaborate version of this type of explanation to account for the behavioral characteristics of low income individuals, argued that a poverty culture exists which "transcends regional, urban-rural, and national differences." While this contention of universality is probably extravagant ${ }^{9}$ (Clark 1965; Liebow 1967; H. Lewis 1968:441), the reaction to the contrary evidence has been to discount the possibility that culture plays any role in the perpetuation of poverty. However, refuting the universality of this concept does not mean that culture is unimportant in every instance of poverty. What has been neglected is precisely the research which would permit specification of the range of conditions under which a cultural explanation is likely to be appropriate.

It is hardly controversial to claim that a diversity of groups live in poverty, and that much of the inter-indi-

The lack of precision in Lewis (1966:xlviii) discussion on the geographic location of poverty cultures makes testing the validity of the universality concept an impossible affair. According to him the poverty culture is (1) universal, yet (2) does not apply to all poor persons. Log. ically, a contention of this sort can never be rejected. It would be correct if the poor in only one nation exhibited the characteristics of the poverty culture, and even if the poor in no nation had these traits. Lewis (1966:li) does state conditions under which the poverty culture is likely to develop, but even in these circumstances it characterizes only a small proportion of the poor (e.g., 20 percent of the poor in America). The culture of poverty therefore seems to be universal in the sense that it exists wherever it exists. vidual variation in response to an anti-poverty program is likely to be explained by the group means. In designing income maintenance programs, for example, allowance is commonly made for different responses (in the size of the work disincentive, in educational investment) according to whether the family head is male or female, able-bodied or incapacitated, young or approaching retirement age. Our contention here is that social groupings will also differentiate among persons in their response to income maintenance and, furthermore, that cultural explanations will be appropriate for some of these groups, situational explanations for others. The importance of investigating the variance in the response is that alternate programs may be necessary to meet the needs of individuals who are unresponsive to an income support arrangement. To the extent that different groups can be associated with one or another of these theories (with respect to particular behavioral characteristics) their adjustments to income maintenance should be more predictable.

One factor which is likely to influence an individual's adaptation to income maintenance is ethnicity. Writing about the West Enders, an Italian community in Boston, Gans (1962:39) maintains that work, for them, is primarily a means of obtaining income in order to maximize the pleasures of life within the family circle; type of work and considerations of job advancement are of secondary importance. "Achievement and social mobility, for example, are group phenomena. In the current generation, in which the Italian is still effectively limited to blue-collar work, atypical educational and occupational mobility by the individual is frowned upon." 
The West Enders provide an example of an ethnic culture which would appear to retard economic mobility since group pressure functions to discourage exceptional attainment. However, an ethnic culture could also support this goal. The dominant Jewish-American and Japanese-American cultures are cases in point. In each, economic achievement and occupational status in the external society are encouraged by the group's values and also rewarded within the ethnic society. ${ }^{10}$

More generally, there is considerable evidence that ethnic affiliation is an important component of social mobility, although there is some doubt as to whether the influence operates primarily through cultural values, or is a residue of the economic opportunities which were available to an immigrant group upon arrival to this country. There are reasons to believe that cultural factors play at least some part. Duncan and Duncan (1968:360), using data which identify the country of origin for native white males of immigrant fathers, report that after controlling for father's SES (education and occupation), some 2.8 grades of schooling still separate the mean scores of the highest achieving and lowest achieving national-origin groups. "Membership

10 An illustration of high occupational attainment in the external society being disvalued within an ethnic group is given by Poll (1962:150). After indicating that the norms of the Hasidic community in Williamsburg discourage Hasidic youth from law training, he writes: "The lawyer is considered a somewhat despicable person. His services are not sought if it can be at all prevented." For an ethnic group to be socially mobile it would seem necessary that a substantial portion of the occupational statuses which are rewarded in the external culture also be accorded prestige within the ethnic group. in a particular national-origin group can rather clearly constitute a substantial "handicap" or "bonus" in the stratification process" apart from the class of social origin. Comparable findings are reported by Katzman (1969:365) in an analysis of the economic position of 14 ethnic groups: "The educational attainment of the second generation is only weakly related to metropolitan educational opportunities and the educational level of their parents. Consequently, we interpret intergenerational gains as an expression of subcultural values."

The intention of the above comments was to indicate that ethnicity may differentiate among persons in many areas of response to an income maintenance program. Extrapolating from the cited material we would sug. gest the following propositions:

(1) The variability of the response across individuals will be smaller among members of an ethnic group in which the traditional culture remains intact (in the sense of retaining distinctive values and institutions) than among individuals who lack an ethnic identity or for whom ethnicity no longer corresponds to a distinctive subculture in America.

(2) Although the presence of an ethnic culture should reduce the withingroup variance, the direction and magnitude of departure of the group mean from the average response by all persons in the program will reflect the particular cultural values. Consequently, among ethnic groups for whom cul. tural values influence the response to income maintenance, we can expect characteristic, and different, average group responses. Among individuals for whom the adaptation is situational rather than cultural, we can expect 
only a large variance in individual response. ${ }^{11}$

These propositions must be qualified in two ways. First, as was indicated earlier, it is likely that with any ethnic group some behavioral correlates of poverty will be best approached through one type of theory, other characteristics through the second type of explanation. Second, the category of individuals upon whom the cultural mores tend to fall most heavily will probably differ by ethnic group. The constraints may be most severe on adult behavior, permitting children considerable flexibility in responding to altered conditions; or they may apply most rigidly to females, restricting their behavior, for example, as secondary wage earners. Research should, therefore, be directed at determining for which categories of persons, among ethnic groups with large numbers in poverty, behavior is likely to be prescribed by cultural mores, and what kinds of behavior are most likely to be so governed.

In the above discussion we have argued that ethnicity is likely to con-

11 It is not possible to distinguish the "psychological maiming" thesis from a cultural explanation by examining the response pattern in this manner. A small variance with a weak group response would result under "psychological maiming" or where cultural values operate to hinder the situationally expected response. To determine the appropriate explanation in this circumstance one must examine the internal organization of the group.

High cultural control over behavior

Single ethnic group in a neighborhood; stable population dition an individual's response to income maintenance in many important ways as it relates to whether his adaptation will be culturally specified or a situational adjustment. A second consideration involves the demographic and organizational characteristics of poor neighborhoods, since these factors will affect the strength of the cultural norms which can be exerted by an ethnic group.

In order for a culturally distinctive group to control behavior effectively it is necessary that an unambiguous rule exist for deciding when the norms of the external system are to be followed, and when the norms of the subculture are operative. Were this not the case, individuals would constantly find themselves cross-pressured, faced with contradictory specifications for behavior. Residential segregation provides one common way for avoiding this dilemma since the operation of the ethnic culture can be tied to geographic boundaries. Moreover, the fact that one resides with others of the same culture permits interpersonal pressure in support of the group's values to be exerted upon a deviant individual, especially when population turnover in the neighborhood is low, so that social bonds are stable. Extrapolating from these considerations, we can scale the likely ability of an ethnic group to control behavior effectively according to the following structural characteristics of a neighborhood:

Low cultural control over behavior

(3)
Multi-ethnic neighborhood; stable population for the under consideration ethnic group borhood; mobile population for the ethnic group under consideration
Multi-ethnic neigh- 
Holding neighborhood composition constant, a major determinant of a group's extent of control over its membership lies in its degree of institutional completeness (diversity of formal ethnic organizations). Residential segregation provides a setting which is conducive to the emergence of ethnic institutions-ethnic schools, churches, newspapers, and social clubs. However, the diversity of organizations which actually develops in a neighborhood will differ by ethnic group, reflecting such considerations as the magnitude of differences between the ethnic and native cultures (Breton 1964). To the extent that these organizations do proliferate, an individual will have more of his social needs satisfied within the neighborhood, be embedded more thoroughly in ethnic networks, and be less likely to violate the expectations of the group. Such an argument suggests, for example, that the response to income maintenance by poor Italians (commonly an institutionally complete ethnic group) would be more closely governed by ethnic values and norms than would be the adjustment by poor Negroes (for whom ethnic institutions are less diverse).

In determining the response to an income maintenance program, these neighborhood characteristics would probably interact with ethnic membership in the following way: where an ethnic group does not place constraints on a behavioral response-deciding whether the wife should seek employ. ment, for instance-the neighborhood social structure would be largely irrelevant to behavior. However, in cases where the ethnic values function either to prevent or encourage a particular adaptation, the organization of the neighborhood should be an important intervening consideration.
In the above discussion we have presented instances in which cultural groups are likely to influence the response to an exogenous intervention such as would be represented by income maintenance. The fact that an ethnic group may impede certain adjustments to income maintenance does not imply that the individuals actually desire to be poor. Rather, it is that the responses which are necessary in order to emerge from poverty are usually individualistic and detrimental to group cohesion, and may conflict with the values and mores which are central in the culture.

\section{ConCIUSIONS}

In the economic literature on income maintenance (Green, 1968; Kesselman, 1969), the analysis of work discentives and other effects from income manipulation proceeds as if, aside from universalistic considerations such as gender and physical condition of the family head, the poverty population can be treated as a homogeneous group. In this paper we have attempted to demonstrate the deficiency of that simplification. It is our contention that the diversity of adaptations to income maintenance which are likely to ensue cannot be adequately understood unless account is taken of the distinct social groups in poverty and of the different mechanisms which can maintain persons in that state.

Field experimentation with income maintenance is designed to answer a number of questions such as which behavioral correlates of poverty will respond to this intervention, what will be the time rate of response by different characteristics and, more generally, how should limited financial resources be allocated to maximize the rate at which individuals are removed from 
economic dependency. An appreciation of the different mechanisms through which persons are maintained in poverty is important to this enterprise for two reasons. This would allow for more efficient programming, enabling the range of response by different groups to be predicted beforehand. Also, if anti-poverty programs are actually to move persons to self-sufficiency and not merely maintain them above the poverty line, then an understanding of the diverse social contexts in which poor persons are embedded is a necessary preliminary for designing successful interventions.

\section{REFERENCES}

Breton, Raymond

1964 "Institutional completeness of ethnic communities and the personal relations of immigrants." American Journal of Sociology 70(September): 193-205.

Clark, Kenneth B.

1965 Dark Ghetto: Dilemmas of Social Power. New York: Harper.

Cohen, Albert K.

1955 Delinquent Boys. New York: Free Press.

Coleman, James S.

1968 "The mathematical study of change," in H. M. Blalock and A. B. Blalock (eds.), Methodology in Social Research. New York: McGraw.Hill.

Duncan, $O$. D.

1969 "Inheritance of poverty or inheritance of race?," in Daniel Moynihan (ed.). On Understanding Poverty. New York: Basic Books.

Duncan, O. D. and Beverly Duncan

1968 "Minorities and the process of stratification." American Sociological Review 33 (June): 356 64.

Duncan, O. D., David L. Featherman, and Beverly Duncan

1968 Socioeconomic Background and Occupational Achievement: Extensions of a Basic Model. Washington, D.C.: Office of Education, U.S. Department of Health, Education and Welfare.
Elesh, David, Jack Ladinsky, M. J. Lefcowitz, and Seymour Spilerman

1970 "The New Jersey-Pennsylvania Experiment. A field study in negative taxation," University of Wisconsin: Institute for Research on Poverty Discussion Paper.

Gans, Herbert

1962 The Urban Villagers. New York: Macmillan.

1969 "Culture and class in the study of poverty: An approach to antipoverty research," in Daniel Moynihan (ed.). On Understanding Poverty. New York: Basic Books.

Green, Christopher

1968 "Negative taxes and monetary incentives to work: The static theory." Journal of Human Resources 3(Summer): $280-88$.

House Committee on Education and Labor 1964 A Report. In Hanna H. Meissner (ed.). Poverty in the Affluent Soceity. New York: Harper and Roe, 1966, pp. 43-67.

Katzman, Martin T.

1969 "Opportunity, subculture and the economic performance of urban ethnic groups." American Journal of Economics and Sociology, 28 (October): 351-366.

Kesselman, Jonathon

1969 "Labor-supply effects of income, income-work, and wage subsidies." Journal of Human Re-

Lewis, Hylan sources 4(Summer) : 275-92.

1968 "Child rearing among low income families," in L. Ferman, J. Kornbluh, and A. Haber (eds.). Poverty in America. Ann Arbor: Univ. Michigan Press.

\section{Lewis, Oscar}

1966 La Vida. New York: Vintage Press.

Lieberson, Stanley and Glenn Fuguitt

1967 "Negro-white occupational differences in the absence of discrimination." American Journal of Sociology 73(September): 188 . 200.

Liebow, Elliot

1967 Tally's Corner. Boston: Little, Brown and Co.

Merton, Robert

1957 "Social structure and anomie," in Social Theory and Social Struc- 
ture. New York: Free Press, pp. 131-160.

Miller, S. M., Frank Riessman, and Arthur A. Seagull

1968 "Poverty and self-indulgence: A critique of the non-deferred gratification pattern," in Louis A. Ferman, Joyce L. Kornbluh, and A. Haber (eds.). Poverty in America. Ann Arbor: Univ. of Michigan Press, pp. 416-432.

Moynihan, Patrick

1966 "Employment, income, and the ordeal of the negro family," in Talcott Parsons and Kenneth B. Clark (eds.). The Negro American. Boston: Beacon Press,

Poll, Solomon pp. 134-159.

1962 The Hasidic Community. New York: Free Press.

Rainswater, Lee and William L. Yancey

1967 The Moynihan Report and the
Politics of Controversy. Cam. bridge: M.I.T. Press.

Stinchcombe, Arthur

1968 Constructing Social Theories. New York: Harcourt, Brace and World.

United States Department of Labor

1965 The Negro Family. Washington, D.C.: Government Printing Office.

Valentine, Charles

1968 Culture and Poverty. Chicago: Univ. of Chicago Press.

Wright, Sewell

1960 a "Path coefficients and path regression: Alternative or complementary concepts?" Biometrics 16(June): 189-202.

$1960 \mathrm{~b}$ "The treatment of reciprocal interaction, with or without lag, in path analysis." Biometrics 16 (September): 423-445.

\title{
DIMENSIONS OF COMMUNTYY RESPONSE TO THE CRIME PROBLEM*
}

\author{
JOHN E. CONKLIN \\ Tufts University
}

This paper examines a number of dimensions of public response to the crime problem. A sample from a high crime rate urban area and a sample from a low crime rate suburban area are compared. The urban sample perceives higher local crime rates than the suburban sample, and it also feels less safe, less trustful of others, and less positive affect for the community than the suburban sample. Relationships between perception of crime and the dimensions of response are stronger in the urban sample than in the suburban sample, suggesting a threshold effect may be operating, with perception of crime affecting dimensions of community life only after that perception has passed a certain level.

In recent years criminology has moved from an exclusive emphasis on the genesis of criminal behavior to a concern with other factors involved in

- Adapted from sections of John E. Conklin, Public Reactions to Crime: A Survey of Two Communities, unpublished doctoral dissertation, Harvard University, 1969. I would like to thank Ann Richardson, Lloyd E. Ohlin, and David J. Armor for their assistance in preparing this paper. the crime problem. Some have stressed the role of authorities in attaching the label of criminal to certain individuals (Becker, 1963; Turk, 1969). Others have examined the role of the victim of a crime, including both the contribution of the victim to a crime (Von Hentig, 1948; Wolfgang, 1958:203265) and the loss suffered by the victim of a criminal act (President's Commission on Law Enforcement and 